A REVIEW OF:

KATE KHATIB, MARGARET KILLJOY, \& MIKE MCGUIRE (2012) WE ARE MANY. REFLECTIONS ON MOVEMENT STRATEGY FROM OCCUPATION TO LIBERATION. EDINBURGH/SAN FRANCISCO: AK PRESS, PP. 355, ISBN-13: 9781849351164.

\&

\begin{abstract}
DAVID GRAEBER (2012) THE DEMOCRACY PROJECT: A HISTORY, A CRISIS, A MOVEMENT. LONDON: ALLEN LANE PRESS, PP. 352, ISBN: 9781846146633.
\end{abstract}

\title{
MARK BERGFELD
}

SCHOOl of Business ANd Management, OUeen Mary University of London

I t is a common sense assumption to emphasise the leaderless, horizontal, networked and demandless nature of the Occupy movement of late 2011 (Penny 2011, Mason 2011, Castells 2012). Two recent publications - Laura Khatib's We Are Many: Reflections on Movement Strategy - From Occupation to Liberation and David Graeber's The Democracy Project - explore the role anarchists played inside of the Occupy movement of 2011.

The two books highlight to what extent anarchists shaped and were shaped by the Occupy encampments strategically, politically and ideologically. They facilitate a better understanding of how these political actors make sense of questions of strategy, organisational practices i.e. consensus decision-making, their demands, or lack thereof inside a mass movement against financial capitalism.

Laura Khatib's We Are Many is a collection of essays which seeks to draw some strategic lessons from the Occupy movement a year after the camps had been evicted. Most of the articles are written by anarchist activists and academics. This resource guide for movement activists combines an eclectic mix of essays, movement stories, and communiqués. Photos and graphics bestow the recent mass movement with a distinct visual imagery. Khatib addresses the purpose of the book in the introduction: "What have we learned over the course of the past year? [...] What lessons do we want to leave for future social movement actors as this movement shifts and grows?" (Khatib et al, 2012, p. 2)

In her essay Is Occupy Over? Frances Fox Piven asserts the role which activist cadres play in shaping the politics of the Occupy movement- She goes on to argue that social movements such as Occupy are "not accidental, only partly spontanous" (Khatib et al, 2012 , p. 373). - just like a combustion. This is the opposite to the kind of horizontalistnetworked practices some activists and commentators have suggested. In the essay The Coming Occupation, Joshua Clover draws attention to how the strongest Occupy camps were based in the cities of New York and Oakland. The underlying reasons for 
this were the preceding student movements of 2009 (95). Again, this dismisses the idea that Occupy appeared from nowhere. Finally, the activist academic collective Occupy Research describes the movement as 'leaderfull' (Khatib et al, 2012, p. 72) transcending the dichotomy of 'leaderlessness' and 'vanguardism'. In doing so, Khatib and others challenge preconceptions about the relation of anarchism and organisation.

David Graeber's book The Democracy Project is written in a similar vein. Acclaimed with coining the slogan of the 99 per cent, Graeber offers us insight into how activists made Adbusters' call to occupy Wall Street a reality. It situates the movement as the second round of the global justice movement but also sees Occupy as a particular American movement. Unlike We Are Many, Graeber writes for a lay audience that might not even have participated in any social movement whatsoever and is merely interested in the Occupy movement. Yet, Graeber actively encourages people in faraway towns and countries to emulate the Occupy movement, or at least draw inspiration from it. According to Graeber the book is "about the opening up of a radical imagination that Occupy allowed". (Graeber, 2013, p. xv)

The first chapter focuses on the summer months leading up to September 17 - the day OWS set up camp. Here, Graeber outlines how he and his friends broke away from the first assembly in August and set-up horizontal working groups. Written in a language which rejects top-down leadership he implicitly advances an alternative vision of the concept of leadership. By re-igniting dormant networks from the global justice movement Graeber and others seize the opportunity and give Adbusters' call a direction. His story's emphasis on individuals' agency and initiative runs counter to to the assumed 'leaderless' and 'spontaneist' nature of the Occupy protests. Unfortunately the implicit nature of these details will get lost in the barrage of attacks on the 'old', 'verticals, and 'socialists'.

In the chapter titled How Change Happens Graeber outlines the organisational practice of consensus decision-making at great length. It could be argued that his anarchism values form over content. In other words, the practice of consensus decisionmaking is more important than the demands or politics put forward by the movement. This is echoed by Khatib who argues that Occupy Wall Street concentrated on process and structure while Occupy Oakland concentrated on tactics and actions (Khatib et al, 2012 , p. 2). In both The Democracy Project as well as the afterword of We Are Many Graeber formulates the concept of 'contaminationism'. The following assumptions give rise to this notion: "the faith that the experience of direct democracy is infectious, that anyone exposed to it will never be the same, that anyone exposing any significant number of people to it would inevitably lead to the creation of a new political culture" (Khatib et al, 2012, p. 425). The idea of 'contaminationism' points beyond some of the technological determinism which authors such as Castells (Castells, 2013) and Mason (Mason, 2012) have fallen prey to. Graeber's description of the collective transformation people experience through their involvement in social movements constitutes his strongest point in the book.

Anarchist practices vary inside of movements. For example, the popular slogan 'Occupy Everything Demand Nothing' and Graeber's call for a 'debt jubilee' stand in clear contradistinction to one another. The former proposition entails three positions: the occupation is its own demand; the wholesale rejection of demands, or the impossibility to meet any demands under the current balance of forces. As Clover puts it "occupation is a tactic. Demandlessness is a strategy.[...] this tactic and this strategy are mutually 
constitutive rather than merely yoked together" (Khatib et al, 2012, p. 100). This kind of prefigurative politics reached its limits once the camps disbanded. Furthermore, it doesn't articulate a counter-hegemonic alternative to neoliberal austerity which social movements so desperately require these days.

In the final chapter Breaking the Spell, Graeber attempts to outline possible steps for Occupy without occupations. He suggests that a 'debt jubilee' could unite more than three fourth of the US population who are now debtors. While rich people have had their debts cancelled in the past this time mortgages, student loans, credit card, and outstanding heating bills would be cancelled. Graeber writes "[...] it is absolutely crucial that, as a social movement, we provide the moral framework, and the political context, in which events are going to take place" (Khatib et al, 2012, p. 430). He is careful not to employ the language of demands yet introduces an ethico-political framework which, in many ways, amounts to the same as arguing for demands - transitional or otherwise. In particular, it is striking that Graeber writes that the ruling class is starting to see the necessity of a 'debt jubilee' (Khatib et al, 2012, p. 432).

In conclusion, We Are Many and The Democracy Project can enhance social movement researchers' and movement-activists' understanding of the Occupy movement and anarchists' role within it. The books' emphases on strategy and organisation mark a valuable shift. It allows for new convergences between so-called 'horizontals' and groups such as trade unionists and socialists. One hopes these lessons will be carried into the next round of mobilizations against capitalism. 